\title{
Entrevista com Silvia Marcia Alves \\ Siqueira: apontamentos para o estudo das representações acerca do masculino e do feminino no Mundo Antigo*
}

\author{
Interview with Silvia Marcia Alves Siqueira: notes on the study of \\ the representations concerning masculinity and femininity in the
}

Ancient World

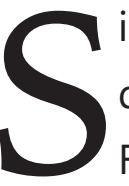

ilvia Marcia Alves Siqueira possui graduação em Ciências Sociais, mestrado e doutorado em História pela Universidade Estadual Paulista Júlio de Mesquita Filho (Unesp), tendo realizado seu pós-doutorado em Roma, na Università degli Studi Roma Tre. Desde 2006 é Professora Adjunta da Universidade Estadual do Ceará (Uece), onde atua na subárea de História Antiga e Medieval executando projetos relacionados à História das Mulheres, à História de Gênero e à Memória. É pesquisadora do Projeto de Cooperação Internacional "Cotidiano, sociabilidades e usos do espaço no Império Romano", desenvolvido no âmbito do Programa Capes/FCT, sob a liderança do Laboratório de Estudos sobre o Império Romano (Leir) da Universidade Federal do Espírito Santo (Ufes) e da Unidade de Arqueologia da Universidade do Minho, Portugal. No âmbito do referido projeto, dedica-se ao estudo dos usos da memória na cultura escrita e na ocupação espacial em Roma, nos séculos IV-V d.C., enfocando os modelos de mulher cristã. Além disso, é responsável, na Uece, pelo projeto de pesquisa intitulado "Representações de mulheres e biografia: florilégios na África romana no Mundo Antigo (séculos I a.C. a IV d.C.).

1. Carolline da Silva Soares e João Carlos Furlani: Ao longo de sua trajetória acadêmica, várias figuras femininas e distintas situações que envolvem questões de gênero mereceram sua atenção, com destaque para as mulheres pertencentes às comunidades cristãs antigas. Como ocorreu seu envolvimento com esse campo de pesquisa?

Silvia Marcia Alves Siqueira: A minha trajetória acadêmica é diversificada e marcada pela interdisciplinaridade. Sou bacharel em Ciências Sociais com mestrado e doutorado em História. Comecei, como muitos pesquisadores brasileiros, com a iniciação científica.

* Entrevista concedida a Carolline da Silva Soares e a João Carlos Furlani em 4 de abril de 2018. 
No meu segundo ano de graduação, candidatei-me a uma bolsa do Conselho Nacional de Desenvolvimento Científico e Tecnológico (CNPq), na modalidade Iniciação Científica (IC), vinculada ao Departamento de Sociologia (Unesp/Araraquara). Tratava-se do subprojeto "Mulher, terra e trabalho no assentamento", que era parte de um projeto maior intitulado "Análise e avaliação dos projetos de Reforma Agrária e assentamento no estado de São Paulo". O objetivo da pesquisa era compreender o trabalho das mulheres no assentamento de Silvânia, lugarejo próximo à cidade de Araraquara, localizada no centro do estado de São Paulo. A experiência de entrevistas, de pesquisa e a convivência intensa com pesquisadoras e pesquisadores me levaram a compreender que a dominação masculina extrapolava as lutas de classes e que as relações entre homens e mulheres são profundamente marcadas por relações de dominação e de poder. Compreendi que os homens narravam a sua história de conquista e luta pela terra, mas as mulheres não demonstravam pertencimento a essa história como sua. Assim, enquanto eles contavam a sua própria história, elas narravam o seu destino de mulher. O significado da história dessas pessoas me marcou profundamente. Essa experiência me colocou frente a frente com a influência da religião cristã na vida daquelas mulheres, pois pude constatar o quanto os textos bíblicos eram citados por elas para justificar o seu "destino de mulher", uma sina amarga presente nas mais diversificadas experiências pessoais e coletivas desde a violência doméstica e cotidiana até o mais singelo ato de alegria. Não foi surpresa constatar que, qualquer que fosse a religião professada por elas, a percepção negativa estava completamente naturalizada à sua vida e o seu destino, inexoravelmente selado. Então comecei meus questionamentos e passei a problematizar a Bíblia como um livro ideológico, repleto de imagens de gênero que justificavam um modelo de mulher negativo e voltado para a aceitação, obediência e docilidade. Nasceu assim a imensa vontade de voltar àquele tempo, entender a formação dos textos fundadores do pensamento cristão ocidental. Foi quando tomei uma decisão chave: sair da Sociologia para a História. Busquei esta área do saber porque tenho a necessidade de circunscrever o tempo em determinado espaço. Em pouco tempo me identifiquei profundamente com esses estudos e não consegui mais viver e refletir fora dos primeiros anos de formação do pensamento cristão ocidental. Mas, sobretudo, me entreguei à difícil tarefa de escrever uma história das mulheres, daquelas mulheres do Mundo Romano de finais do segundo século até o sexto século, um recorte temporal significativo e decisivo. Assim, escolhi a pesquisa histórica justamente como um dos caminhos possíveis para contribuir com a formação positiva das mulheres atuais, evidenciando que a narrativa histórica, durante muito tempo, teve o recorte de gênero como pressuposto. Portanto, é fundamental produzir e pensar que as mulheres também viveram, pensaram, atuaram e contribuíram para a História, e não há como compreender 
qualquer que seja a época sem considerar todos os elementos envolvidos. Por muito tempo, a História foi escrita pelos vencedores, principalmente para consolidar seu poder, e é justamente a manutenção do domínio que faz com que ela seja transmitida, ensinada e memorizada, forjando-se uma suposta verdade que tem sido naturalizada.

2. No Brasil, durante décadas, os estudos envolvendo sexualidade, lugar social e papéis femininos foram realizados sob o prisma da História das Mulheres. Contudo, a partir da década de 1990, observamos uma notável predominância do emprego do conceito de gênero nos trabalhos dedicados a iluminar o universo feminino, o que de certa maneira favorece o diálogo entre temáticas do passado e do presente. Nesse sentido, de que maneira o conceito de gênero foi recebido e empregado pelos especialistas em História Antiga?

R: Esta questão é bastante complexa e exige um estudo específico para respondê-la. Acredito não estar apta para analisar a recepção e o uso do conceito de gênero no Brasil, mais especificamente na História Antiga. Se hoje aborda-se o tema "mulheres" no plural, em detrimento da mulher, no singular, é porque foi possível libertar a temática da transcendência do "eterno feminino" e colocá-la em uma abordagem relacional, inaugurada pelos estudos de gênero, sobretudo mostrando que o sexo não é um dado biológico e natural, mas uma "construção social", cujo significado sofre alterações de acordo com o período e o local tratados. Enfim, além de um sexo biológico, há também um "sexo social" que é determinado pela comunidade e desenvolve-se em determinado espaço e tempo, portanto pode e deve ser situado historicamente. Desde a publicação, em português, da coleção História das Mulheres no Ocidente, na década de 1990, assistimos à fermentação de estudos dessa natureza no País, que analisam as práticas sociais e as estruturas de pensamento, entrelaçando homens e mulheres na mesma história, evitando tratar das mulheres como uma categoria isolada, estudando as relações entre os sexos no âmbito de uma análise mais ampla do modo de funcionamento das sociedades antigas. Esses estudos, em particular, e a discussão do estatuto epistemológico da História, seguramente, muito influenciaram as pesquisas de estudiosos e estudiosas brasileiros(as). Desde então, cresceu o número de estudos sobre mulheres no Mundo Antigo no Brasil, com problemáticas variadas. Multiplicaram-se, também, os métodos empregados, que se preocuparam desde cedo em discutir os referenciais teóricos de gênero presentes na crescente produção historiográfica, situando-os nos debates teóricos mais amplos e marcando um distanciamento diante de simplificações conceituais. 
3. Em sua opinião, ocorreu, de fato, a incorporação das teorias de gênero às pesquisas em História Antiga, em especial àquelas realizadas no Brasil, ou a aplicação dessas teorias tem se revelado superficial?

R: Hoje, no Brasil, tem aumentado significativamente os estudos que empregam as teorias de gênero, não obstante o pouco número de pesquisas que se ocupam da Antiguidade. Quanto à aplicação, acho que esta varia substancialmente, havendo abundância de trabalhos que apenas aplicam as teorias, sem uma crítica mais aprofundada. Em menor número, é possível encontrar revisões teóricas. Entretanto, acredito que estamos amadurecendo muito nesse campo. As teorias de gênero abrigam, em sua natureza, a multidisciplinaridade e a interdisciplinaridade, especialmente em relação à compreensão dos significados sociais e culturais da sexualidade e da identidade, de modo geral, e da identidade de gênero, de modo específico. Assim, o campo do saber estabelece claramente uma subdivisão tanto no plano teórico e conceitual quanto em relação aos dois aspectos da identidade. É uma temática complexa. No entanto, é possível vislumbrar uma nova geração despontar com grande intensidade e acredito muito nos trabalhos futuros.

4. Observamos ainda certa confusão, mesmo em se tratando dos pesquisadores, entre o campo da História das Mulheres e o dos Estudos de Gênero, como se as questões de gênero se restringissem ao âmbito feminino. No caso da Antiguidade, qual seria a melhor maneira de aplicar esses dois approaches de modo a torná-los mais produtivos?

R: Esta questão me faz refletir sobre o uso de conceitos da sociedade moderna para o Mundo Antigo. A História naturalmente se refere à diferença dos mundos e dos sujeitos envolvidos. Estou aqui refletindo sobre a historiografia das mulheres. Lembrando que os principais objetivos da História das Mulheres gravitam em torno da vontade de conferir visibilidade à presença feminina como sujeito histórico, trazendo as mulheres para a narrativa histórica. Mas é também seu escopo historiar o gênero como uma construção social e cultural e não como um dado natural, imutável, de modo que a diferença entre o homem e a mulher é natural, mas a relação entre eles é codificada a partir de uma construção cultural que se tornará também social.

Por outro lado, os Estudos de Gênero defendem que a palavra gênero automaticamente remete para a questão de que a diferença entre o masculino e o feminino não coincide com a definição do diferencial entre os machos e as fêmeas porque as características (ou os estereótipos) do gênero resultam de uma construção 
cultural. Assim, os Estudos de Gênero contestam as teorias que consideram naturais as desigualdades entre os sexos e as diversificações entre homens e mulheres, defendendo a ideia de que é possível construir a igualdade considerando as diferenças. Assim sendo, o termo gênero automaticamente relativiza o fundamento biológico, portanto natural, da diferença entre os sexos: a feminilidade, a masculinidade, a heterossexualidade e a maternidade não são considerados naturais, mas sim "culturais", não são definitivos e, sobretudo, não são determinantes. Em última instância, utilizar o termo gênero no lugar de sexo exclui a possibilidade de definir a pessoa a partir de sua estrutura biológica (corpo), comparecendo dessa forma a possibilidade de definir a pessoa a partir de sua autocompreensão psicossocial.

Usar esta ou aquela categoria interpretativa depende muito da documentação disponível. Ambos os enfoques podem ser úteis: na História da Mulheres, a diferença natural entre homens e mulheres se desdobra nas divisões dos papeis sociais e nas atribuições das tarefas e espaços, muitas vezes a partir de uma dualidade (família/ privado, política e economia/espaço público) desequilibrada e hierárquica, privilegiandose o masculino. As regras, as normas e as representações multiplicam e disseminam a hierarquia porque permitem manter a ordem social por meio da estabilidade da família, por exemplo. Quanto ao conceito de História de Gênero, pode-se, por meio dele, verificar como são codificadas, mantidas, revisitadas ou mesmo alteradas as relações entre os gêneros em diferentes níveis (nas normas, nos comportamentos, nas representações simbólicas, em suas respectivas articulações e ambiguidades internas). Esta abordagem possibilita uma leitura histórica diversificada e ramificada em diferentes redes de códigos, que negociam constantemente entre si por meio de comportamentos individuais, associações e movimentos coletivos.

5. Notamos que a maioria das pesquisas em História Antiga que utilizam o conceito de gênero busca analisar situações e discursos envolvendo as mulheres num contexto dominado pela figura masculina. Mas e os homens? De que maneira os estudos de gênero têm abordado o papel do homem na Antiguidade?

R: Parece evidente que os estudos de gênero tratam do aspecto relacional entre ambos os sexos. As identidades de homens e mulheres são construções sociais, culturais e políticas complexas. Tais constructos são diversos conforme seus respectivos contextos históricos e geográficos. Qualquer que seja a identidade, ou as identidades, é sempre bom lembrar que se trata de homens e mulheres plurais e raramente cabe o singular, o estudo de um simples indivíduo. Muito mais do que uma história das mulheres, trata-se de uma 
história da relação entre os sexos e também do que define respectivamente identidade e alteridade. Enfim, uma história relacional que coloca em causa toda a sociedade, dos elos entre os sexos; e, portanto, também é a dos homens.

6. Uma limitação evidente dos estudos de gênero no Mundo Antigo, em especial daqueles que enfatizam o universo feminino, diz respeito à escassez de testemunhos produzidos pelas próprias mulheres. Como lidar com essa situação?

R: O que tem sido feito é um investimento na diversificação da documentação analisada, bem como no uso de teorias que contribua para refletir sobre uma sociedade complexa permeada pela pluralidade e diversificação. Os diferentes testemunhos devem ser considerados em seus respectivos contextos históricos e culturais, e analisados mediante abordagens plurais, capazes de evidenciar a complexidade das práticas sociais que estão inscritas em gestos, espaços, hábitos, situações, sensibilidades e circunstâncias que mudam de acordo com a época. Há trabalhos muito interessantes que tratam da cultura escrita e da oralidade no Mundo Antigo, contribuindo para entendermos melhor as mulheres, ainda que predominem a exclusão, as limitações bem como as próprias reclusões.

7. Afirmar que um trabalho empreende uma investigação sobre as relações de gênero não explica muita coisa, pois um recorte temporal, uma definição espacial, a formulação de uma problemática e a seleção dos documentos são procedimentos indispensáveis. No entanto, sabemos que, na escolha de um objeto de pesquisa, por vezes, determinados assuntos em voga acabam sendo privilegiados, em detrimento de outros, potencialmente interessantes. Atualmente, é possivel observar uma tendência ou alguma temática mais comum associada aos estudos de gênero na Antiguidade?

R: No Brasil, ainda são poucos os trabalhos sobre mulheres no Mundo Antigo. De modo geral, muitos deles tratam dos papeis femininos, das identidades, do casamento e da ação no espaço público e privado. Particularmente, penso que é necessário ainda um olhar muito cuidadoso para os estereótipos que comparecem abundantemente nos textos. Vejo a necessidade imperativa de repensar as categorias interpretativas, as estruturas e os modelos de mulheres nas fontes documentais, valorizando a especificidade da mulher em qualquer recorte temporal. É preciso muita atenção ao discurso sobre como a cultura discute, circunscreve e cria determinadas questões sobre as mulheres. Não é fácil chegar a uma realidade aproximada da vida das mulheres do Mundo Antigo. Aquelas que tenho pesquisado tiveram oportunidade de escolher a vida ascética. Se considerarmos os 
seus biógrafos, algumas contestaram os ideais de gênero e fizeram escolhas, por vezes contrariando as expectativas sociais. Mesmo relativizando todos os aspectos retóricos presentes nos documentos, é possível encontrar contradições e pistas indicadoras de que a mulher tem um espaço específico de ação onde ela pode atuar no próprio discurso social estabelecido como modelo ideal e criar um modelo próprio.

8. Os estudos de gênero mudaram bastante desde a década de 1980. A desconstrução dos discursos sobre o feminino e o masculino foi aprofundada, a dualidade entre os sexos foi cedendo lugar às teorias queer segundo as quais o constructo social interfere diretamente na definição dos gêneros, não existindo papéis sexuais essencial ou biologicamente inscritos na natureza humana. Tais princípios teóricos têm encontrado, nas pesquisas sobre temas contemporâneos, uma larga aplicabilidade. Contudo, no que se refere à Antiguidade, seria viável a sua aplicação?

R: Tenho pouco contato com a teoria queer. Acho que é um desafio teórico significativo e fadigoso. Sei que, desde o início, os filiados a esse ramo de estudo têm se pautado pelo debate, algumas vezes tenso, outras vezes solidário, com as Ciências Sociais, em particular com a Sociologia. Esta corrente teórica nasceu no berço filosófico e na crítica literária nos Estados Unidos nos idos de 1980 com o objetivo estabelecer um contraponto com os estudos sociológicos que se ocupavam das minorias sexuais e de gênero, bem como da política identitária dos movimentos sociais. Enfim, são estudos que se localizam em uma área de fronteira do conhecimento entre a Filosofia, os Estudos Culturais norteamericanos e o Pós-Estruturalismo francês. Eles aplicam conceitos e métodos diversificados para problematizar as definições clássicas de sujeito, identidade, agência e identificação.

O desejo e a sexualidade ocupam um lugar central na teoria queer. Para estudálos os teóricos focaram os discursos relativos aos saberes sexuais a partir de um método desconstrutivista, deixando de lado a construção social das identidades, os comportamentos sexuais classificatórios e relativizando os processos sociais normalizadores, baseados em classificações que definem os sujeitos estáveis, identidades sociais e comportamentos coerentes e regulares. Busca-se compreender a forma como o desejo e a sexualidade estruturam a ordem social contemporânea a partir da avaliação de sujeitos sociais instáveis, demonstrando como os processos sociais normativos e classificatórios estabelecem as ilusões dos sujeitos estáveis, cujas identidades sociais e comportamentos parecem coerentes e regulares. A minha questão é: o conjunto de documentação disponível para o Mundo Antigo possibilita entender a forma como o desejo e a sexualidade estruturam a ordem social, na medida em que, para esta vertente, nenhuma face da vida social 
pode ser compreendida sem uma análise cuidadosa de como os significados sexuais se interseccionam na sociedade objeto de estudo? Por outro lado, é necessária atenção crítica aos processos normalizadores, de modo a elaborar uma desnaturalização do social. Desse modo, é preciso refletir muito e conhecer profundamente os aportes teóricos e verificar a possibilidade de aplicação para compreender as questões do Mundo Antigo. Nesse sentido, a relação entre poder e sexualidade não pode ser respondida linearmente, pois ela própria comporta uma abertura enorme de dimensões plurais, uma área desconfortável da teoria crítica que tem impulsionado conflitos em múltiplos ambientes.

9. Em outubro de 2017, Judith Butler, uma das mais importantes e reconhecidas teóricas dos estudos de gênero na atualidade, foi convidada a participar de um evento, em São Paulo. Na ocasião, foi recebida com hostilidade por um grupo de manifestantes, que chegaram inclusive a gritar "queimem a bruxa". Uma das explicações para esse posicionamento reside na aversão, por parte de alguns, aos conceitos de gênero e às teorias queer e na associação da filósofa com a comunidade LGBT. Um mês após o ocorrido, Butler escreveu um artigo, publicado na Folha de São Paulo, no qual comentou os ataques sofridos. Em sua declaração, afirma que um grande mal-entendido decorre da falsa ideia de que as teorias de gênero constituiriam uma ideologia. Gostaríamos que a senhora comentasse essa declaração.

R: Este episódio é lamentável e vergonhoso. Trata-se de um retrato que evidencia uma realidade de intolerância, desrespeito e ignorância profunda. O debate é bastante complexo, parece evidente que há uma reação conservadora às conquistas das lutas feministas e dos movimentos LGBTQI, que reivindicam a desnaturalização da ordem sexual imposta e a subversão da ordem heteronormativa. Pode ser também a total negação da intensa produção científica que está inaugurando uma nova área do conhecimento, que se ocupa predominantemente em compreender o funcionamento das diferentes formas da ordem sexual e suas respectivas hierarquizações e normas, como elas são representadas e como são naturalizadas. Pode ainda representar reações ao desdobramento de reformas jurídicas ou mesmo de políticas públicas direcionadas ao combate à discriminação contra as mulheres e pessoas "fora das normas". Mas essa questão ainda pode ser mais complexa se pensarmos que o conjunto discursivo que defende o gênero como uma ideologia reúne diferentes correntes teóricas como se fosse uma única e atinge um único alvo que é composto por múltiplos atores que não estão de acordo entre si, como, por exemplo, o próprio significado de gênero. Enfim, as distorções e deformações conceituais têm sido difundidas por meio de diferentes meios de comunicação de massa e têm influenciado grupos que protagonizaram e protagonizam acontecimentos infelizes como 
a manifestação contra Judith Butler no Brasil. Acho que a violência inscrita nessa "caça à bruxa" indica que a radicalidade crítica do conceito de gênero é a imagem do embate entre as diferentes maneiras pelas quais uma sociedade pensa a sua ordem sexual, as suas divisões e as suas relações.

10. Recentemente, a senhora participou de um projeto de cooperação internacional entre a Universidade do Minho, a Universidade Federal do Espirito Santo, a Universidade Federal do Pará e a Universidade Estadual do Ceará, no âmbito do Programa Capes/FCT. Poderia nos relatar a importância dessa experiência, na fronteira entre a História e a Arqueologia, para os temas de gênero que, no momento, investiga?

R: Ganhei muito ao participar do projeto "Cotidiano, sociabilidades e usos do espaço no Império Romano" coordenado pelo Prof. Dr. Gilvan Ventura da Silva. A experiência tem sido muito positiva e coroada de aprendizado e, sobretudo, de muita motivação para continuar meus estudos. Pude ampliar as minhas pesquisas no âmbito do subprojeto "Clarissimae feminae: propaganda, modelo e identidade da mulher cristã. Estudo da memória na cultura escrita e na ocupação espacial em Roma dos séculos IV-V d.C.". Inicialmente, procurei analisar, compreender e contextualizar o período em que patronato e o evergetismo presentes nos textos, em discursos que destacam a benemerência e a caridade, passam a atuar como agentes de propaganda a favor da constituição de modelos e identidade de mulheres cristãs. Por meio da análise de um conjunto de textos que compõem uma cultura escrita significativa nos séculos IV e V d.C., e também no estudo da ocupação espacial da cidade de Roma, especialmente igrejas e catacumbas, tem sido possível problematizar que a busca pela perfeição naquela época está intimamente registrada na questão espacial, em uma geografia física, especialmente porque o primeiro passo na busca da vida perfeita estava no ato de visitar os lugares santos. Daí as várias mulheres que estudei viajarem muito, buscarem conhecer não apenas a terra onde Jesus viveu e pregou, mas também os locais habitados pelos santos e monges do deserto. A história dessas mulheres evidencia o social e o espiritual, sobretudo porque a escolha religiosa proporcionou mobilidade para os lugares definidos então como espaços de santidade. A interdisciplinaridade tem sido uma experiência enriquecedora. A Arqueologia é uma área do conhecimento que tem contribuído de forma efetiva para repensar a questão da divisão espacial entre homens e mulheres. Ela nos faz ver espaços compartilhados e muitas vezes não sexualizados. Da mesma forma, há a questão do público e do privado que, em última instância, faz dos gêneros modelos interpretativos fechados e presos em determinados espaços. A interdisciplinaridade proporciona um olhar mais amplo e enriquecedor para 
a questão das mulheres no Mundo Antigo. Ainda que cada qual tenha os seus limites teóricos e metodológicos, há uma conexão profunda entre a História e a Arqueologia, o que dificulta a fixação de limites bem definidos entre uma e outra disciplina. Tudo o que posso dizer é que tenho aprendido muito. A ponte construída com este projeto deve continuar, pois os objetivos têm sido coroados de êxito e há indicadores de que é possível colher ainda muitos outros frutos dessa parceria. 